\title{
Emergent chemistry
}

The development of abstract thinking in preschool science education

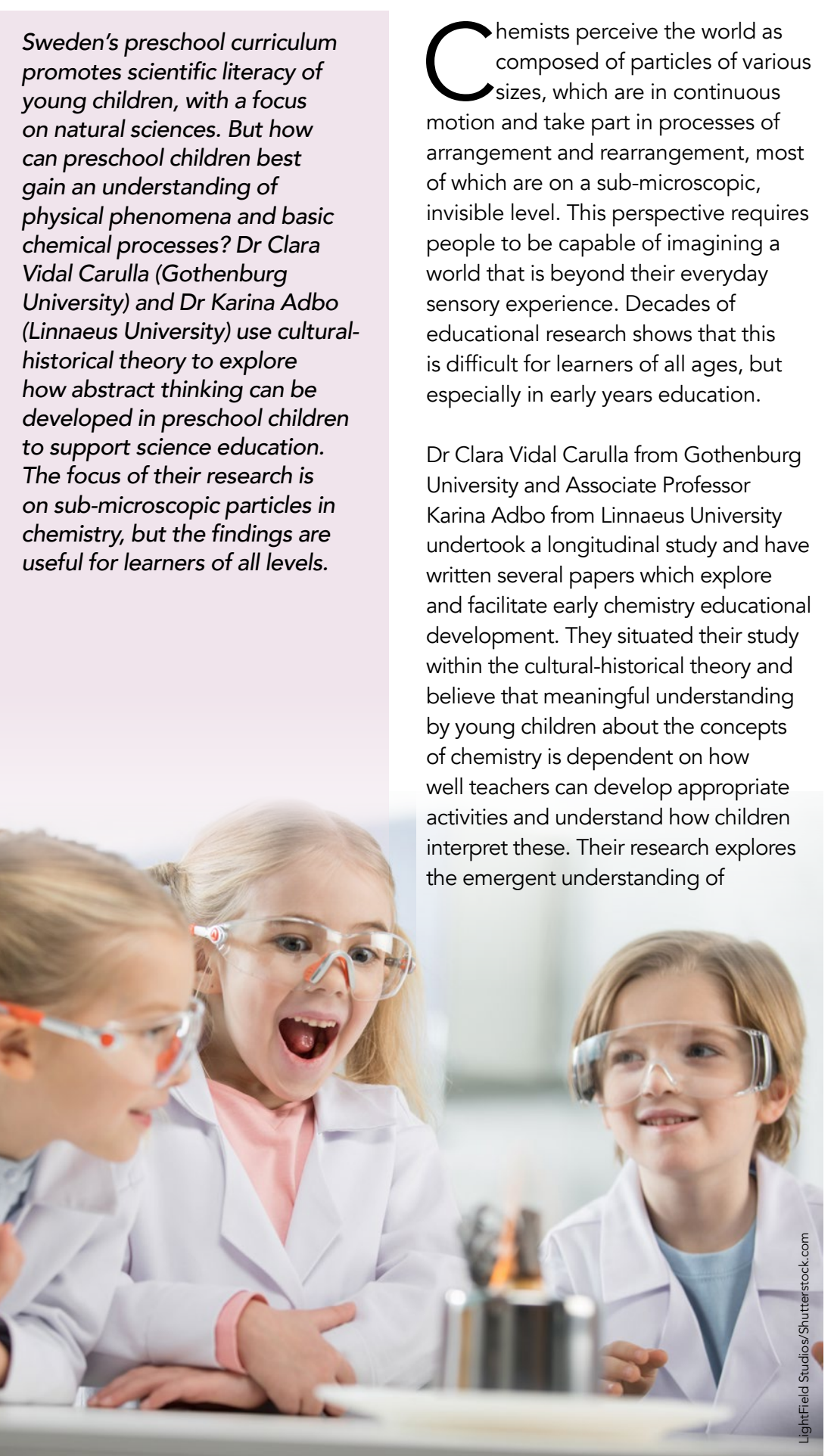

abstract concepts in chemistry throug maginative play-based learning and sustained shared thinking.

CULTURAL-HISTORICAL THEORY The team's research is underpinned by cultural-historical theory $(\mathrm{CHT})$, which indicates that human development is a complex dialectical process. This means through dialogue and discussion between two people or more. $\mathrm{CHT}$ therefore highlights the whole of a child's social encounters and their interpretation of these as having an impact on their development. A child's development is in relationship, or dialectic, with their social world. The theory stands in opposition to monistic (human development occurs in an individualistic, purely biological manner) or dualistic (body and mind) approaches to human development.

Contemporary $\mathrm{CHT}$ has become a comprehensive theory of development that is inclusive, embracing both the personal and the social aspects of learning and development. It defines provide possibilities for new activities and the internalisation of social interactions. While this is a generally applicable process, it does not occur in the same manner for all learners.

$\mathrm{CHT}$ recognises learning as an emotionally sensitive, dynamic, and individual process. This is due to its acceptance that each person has different ways of viewing and interpreting the world. Each person has their own 'prism' or way of interacting with, paying attention to, and interpretating their social world lifentified by some as their unique of edurld experiences. Within the world of education, learning is dialectical:



understanding and behaving through perction with their social word

SUSTAINED SHAPED THINKING

of scientific terms through their role modelling and feedback.

PLAY-BASED LEARNING AND

SUSTAINED SHARED THINKING The term sustained shared thinking is $\quad$ CHT highlights the social perspective used in situations where the teach
and children work together, expanding each child's everyday experiences. Dr Clara Vidal Caru and Dr Karina Adbo pointed to several areas of importance for sustained share thinking in early childhood chemistry education. They state the quality of the together is crucial Alongside wis, the teacher and all the children need to contribute to the discussions by voicing their thoughts and reflections. This should involve them being engaged in open-ended questions. As part of this, the teacher needs to provide the children with formative feedback as well as modelling desired behaviour.

Sustained shared thinking fits in with the dialectic of CHT and play-based educational pedagogy developed from Vygotsky's scaffolding theory. The teacher has a key role in sustaining the discussions and actively participating in them. At the same time, the teacher positive in learning science driven by exploration children's emerging knowledge is a it is antipited chidren will express is anticipated children will express children's emergent knowledge or mor specifically 'emergent chemistry' is used to refer to children's expressions of interest and understanding of the phenomena, in this case, chemistry.

Within this pedagogy, based on the scaffolding theory of Vygotsky further developed by educational researchers, an important aspect of learning in playbased settings is imagination. This is believed to facilitate the development of abstract thought. Abstract thinking enables the generalisation of experiences across different contexts - for example, atoms can be found in leaves and in water. The scaffolding theory has affective seen as necsang for helping children move from inter-personal to intra-person functioning: internalising and making sense of knowledge from teacher and

peer conversations peer conversation

Contemporary educational theory recognises abstract thought as building $\begin{aligned} & \text { Swiss psychologist } \\ & \text { Jean Piaget believed }\end{aligned}$ n everyday sensory experiences which abstract thought to astract thought to the age of eleven years or older. He also recognised developing imagination. of scientific phenomena and positive mathematical understanding. engagement. Within this context, Contemporary educational theory,




however, recognises abstract thought as building on concrete thoughts, such


developing imagination.

\section{HANDS-ON EXPERIENCE OF}

CHEMICAL PHENOMENA

The studies conducted by Dr Vidal Carulla and Dr Adbo explore children's emerging bility to use abstract thought through magination to develop understanding of chemistry concepts. To enable capture and analysis of the children's activities and discussion, the researchers used visual ethnography. This allowed for researcher paristipation and detalled scrutiny of the interactions through
of video cameras.

Play-based learning activities were designed and implemented to provide phenomena and to explore children's reasoning regarding these phenomena. This facilitated exploration of children's skill attainment and interpretations

of science.

The play-based learning activities included deconstruction of everyday items and the use of magnifying glasses and microscopes. They were supported by the teacher who - throug sustained shared thinking - led the children's discussions and reflections about their interpretation of what they were experiencing. The children at this age had limited verbal language ths and so at in es expressed their certand behaved The activities in luded using a mortar, magnifying glass and misring a o view known objects such as leaves. These were further developed by inclusion of animated clips showing the transition from everyday size to 'small'. Through sustained shared thinking, the teacher was able to address both cognitive and affective domains. This facilitated the elicitation of the children's understanding of the transition from macroscopic to microscopic scale and their positive motivation

THE WORLD OF THE MICROSCOPIC The results from the play-based activities hid not provide enough support for the childrento mald to she
At this stage they simply described the These results can be part of solving the te to the particles they saw under the magnifying glass as big.

It was not until DrVidal Carulla and Dr Adbo provided the children with computer animations zooming in from the macroscopic to the sub-microscopic level that the children were able to mo beyond everyday descriptions. The transformed into rocognition that thing may not be exactly what they seem, a realisation that is important in abstract thinking. The visual experience of the tevels can be supported to understand chemistry concepts.

\section{CONCLUSIONS}

There are many conclusions that can be drawn from this research project. Primarily, demonstrated that chemistry does have methods are accessible to young children who can develop abstract thinking when provided with appropriate visual aids and sustained shared thinking. It is important that both cognitive and affective aspects of preschool science education are considered in order to create positive

It is important that both cognitive and affective aspects of preschool science

education are considered in order to create positive attitudes and motivations

$$
\text { for science. }
$$

children to express their understanding of The teaching or leading of science 'small' to encompass the sub-microscopic. education for early years children

The CHT has been useful in the exploring requires skiffl practitioners who can children's development of chemistry build knowledge and understanding understanding and abstract thinking. through sustained shared thinking which Within this, both cognitive and affective emerge from the children's everyday domains need to be addressed through experiences. Teachers' ability to develop sustained shared thinking, scaffolding and encourage these conversations and the social environment which are all and children's peer discussions re an imponant part of a chl

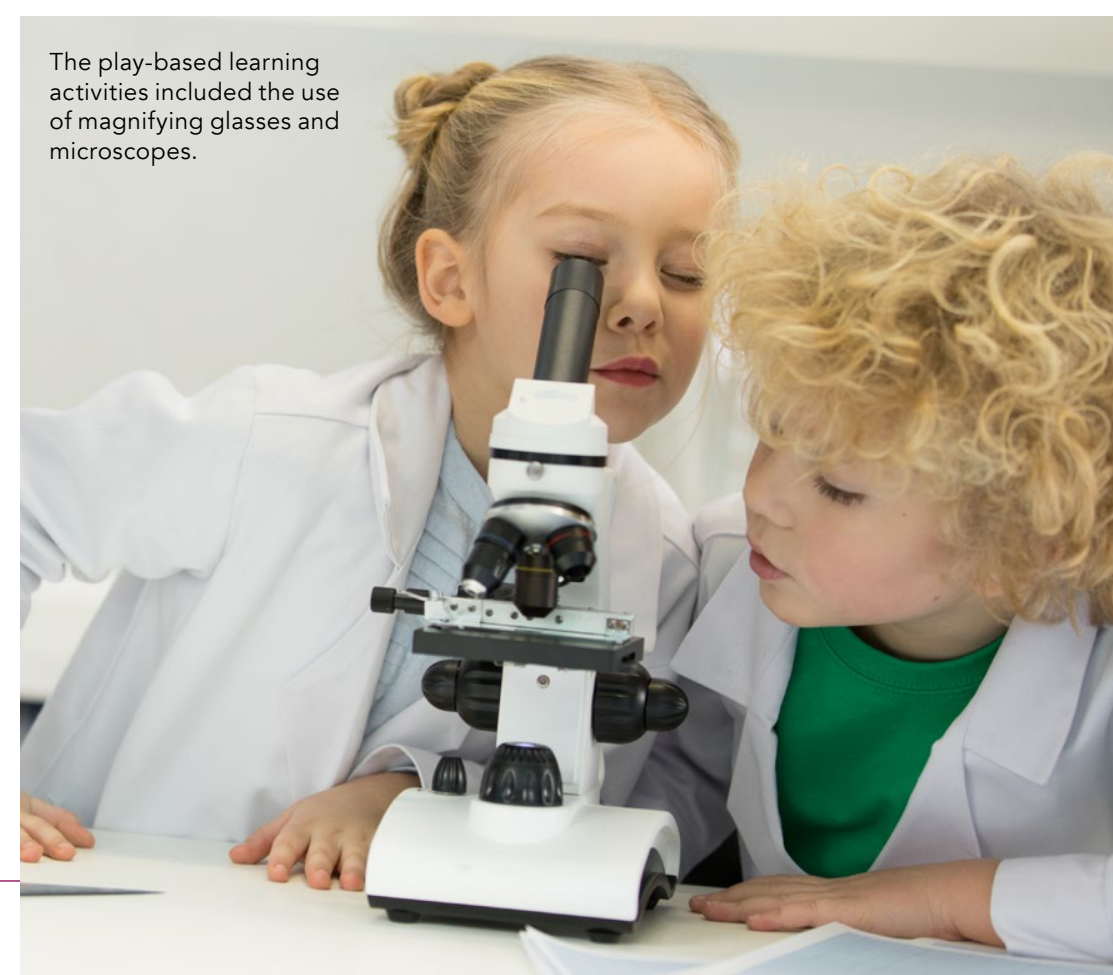

\section{Behind the Research}

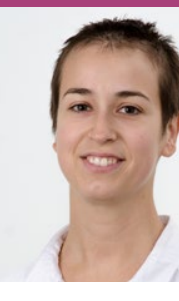

E: clara.vidalcarulla@|nu.se T: +46763281767

\section{W: https://orcid.org/0000-0002-0211-9457}

Research Objectives

Drs Clara Vidal Carulla and Karina Adbo explore children's emerging understanding of abstract thinking in chemistry.

\section{Detail}

\section{Address}

Norra Kajplan 6
39247 Kalmar

39247 Kalmar

$$
\begin{aligned}
& \text { Bio } \\
& \text { Dr Clara Vidal Carulla gained } \\
& \text { her PhD at the Faculty of Health } \\
& \text { and Life Sciences, Linnaeus } \\
& \text { University. Since August } 2021 \\
& \text { she works at Gothenburg } \\
& \text { University. Her research focuses } \\
& \text { on the emergence of science in } \\
& \text { the preschool setting. }
\end{aligned}
$$

\section{References}

Adbo, K. \& Vidal Carulla C (2020) Learning About Science in Preschool: PlayBared Activitios to Support Children's Understanding of Chemistry Concepts International Joun of Early Childhood, 52, 17-35. Available at: https://doiorg/10.1007/s13158-020-00259-3

Adbo, K. \& Vidal Carulla, C. (2019). Designing play-based learning chemistry activities in the preschool environment. at. https//doiog/10.1039/C8RP00306H

Vidal Carulla, C. \& Adbo, K. (2020). A study of preschoo children's motive orientation during science activities. Review Available at: https://doi.org/10.26220/rev.3346

Vidal Carulla, C. \& Adbo, K. (2019). Using Cultural-Historical Theory to Design and Assess a Chemistry Play-Based Learning Intervention. Cultural-Historical Psychology, 15(4), 35-43.

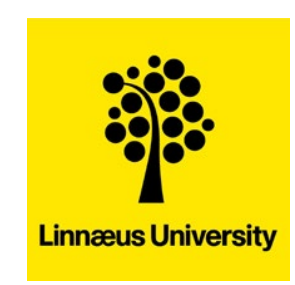

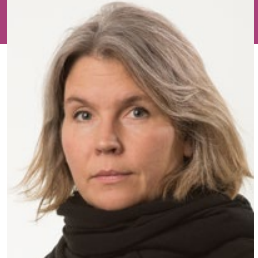

Dr Karina Adbo

\section{T: +46738248569}

(1)

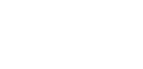

